Ringmicrometer-Beobachtungen des Cometen 1. 1861, von Herrn E. Kayser in Danzig.

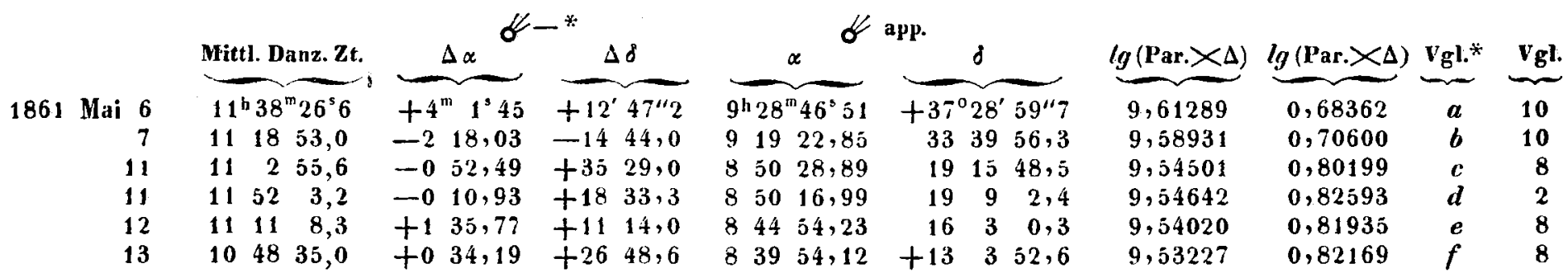

Mittlere Örter der Vergleichsterne für 1861,0 mit Bezug auf Wolfers' Tab.

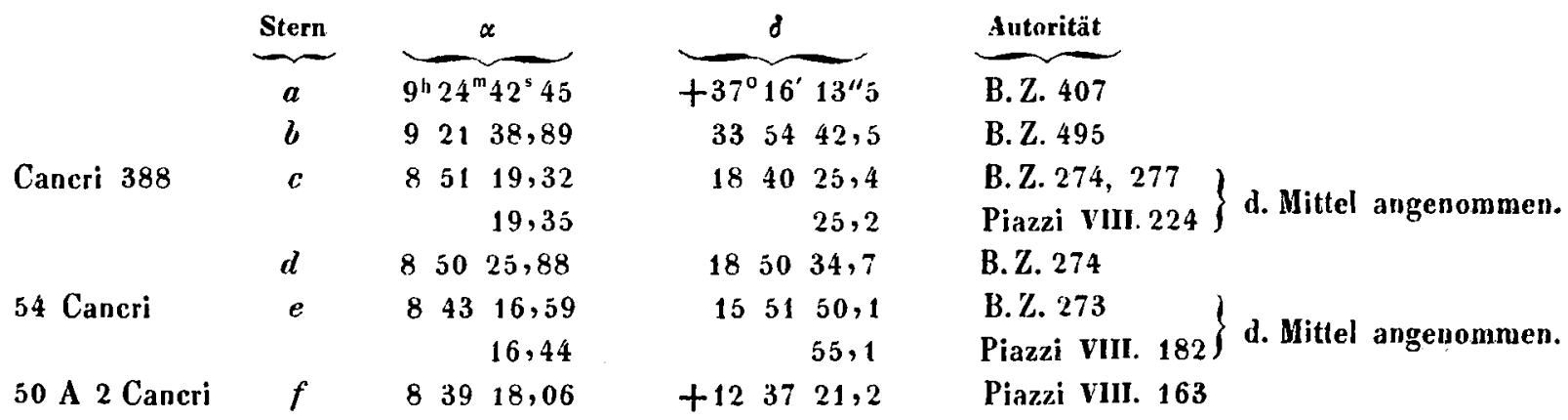

$$
\text { B e m e r k u n g e } n \text {. }
$$

Diese Beobachtungen sind im Locale der naturforschenden Gesellschaft mit den 42 zöll. Instrument von Fraunhofer angestellt worden. Der Comet erschien als rundlicher Nebel mit nicht besonders dichtem Kern. Den Schweif konnte ich nur am $4^{\text {ten }}$ und $7_{\text {ten }}$ Mai erkennen, am erstgenannten Tage

Danxig 1862 Januar. betrug die Schweiflänge etwa $33^{\circ}$, und erschien derselbe als Strich; am 7ten Mai sab ich einen schwachen Schimmer von Schweif $12^{\circ}$ lang. Bei den Vergleichsternen $c, e$ und $f$ giebt der Piazzi'sche Catalog eigene Bewegung an, diese ist in der Reduction auf 1861 herïcksichtigt.

\section{E. Kayser.}

\title{
Die Sonnenfinsterniss am 31. December 1861.
}

Von Herrn J. F. Julius Schmidt, Director der Sternwarte in Athen.

In Folge der genauen Rechoung des Herrn Dr. Weiss in Wien veränderte ich meinen ursprünglicben Reiseplan und beschloss, da ich auf eine grössere Reise diesmal obnehin verzichtete, mich nur in den nördlichen Theil des Peloponnes zu legeben, und zwar in das Gebiet von Nemea und Phlious, wo die Sonne total verfinstert untergehen musste. Am $25^{\text {sten }}$ Dec. verliess ich Athen, reiste Dec. 26 über den korinthischen Isthmos, wo ich das grosse Erdbeben von Aigion erlebte und ging Dec. 29 den Longopotamos hinauf, über Kleonä und Nemea nach Hagios Georgios am sürllichen Fusse des Trikaranon. Das Welter war stets überaus scblecht gewesen. Am $30^{\text {sten }}$ Dec. heiterte es sich vollkommen auf und ich erstieg den Berg Polyphengos, den ich für die Beobachtung drr Finsterniss gewält hatte; denn die Koilossa (Me- galo Vouno) war ehenso wie die andern grossen kahlen Felsherge wegen der mächtigen Schneelager und der pfadlosen unbewohnten Wildniss ganz unzugänglich. Der $31^{\text {te }}$ Dec. war vollkommen trübe und die Sonne kam keine Secunde zum Vorscbein: es regruete oft hei Nordwind. Dennoch begah ich mich wieder auf den gegen 300 Toisen bohen Polyphengos und stellte das Fermrohr neben der alten Ruine auf. Undurchdringliches Gewölk deckte den Himmel und verhüllte bis 350 Toisen abwärts alle Berggipfel. Um $3^{h} 53^{m}$ (mittl.Zt. Athen) streifte fern im Südosten Sonnenlicht durch die Ebene von Argos; dort blieb der Sonnenschein in drei langen feuerfarbigen Reiben, mehr und mebr crblassend, wie die Finsterniss zunahm, bis zum Untergange der Sonne, und in ihrem Lichte sah ich Mykenai, Tiryns und Nauplia, wo $2^{*}$ 